\title{
Intensity dependence of auditory P2 in monozygotic twins discordant for Vietnam combat: Associations with posttraumatic stress disorder
}

\author{
Linda J. Metzger, PhD; ${ }^{1-3^{*}}$ Roger K. Pitman, MD; ${ }^{1-3}$ Gregory A. Miller, PhD; ${ }^{4}$ Stephen R. Paige, PhD; ${ }^{5^{*}}$ \\ Scott P. Orr, $\mathbf{P h D}^{1-3 \dagger}$ \\ ${ }^{1}$ Research Service, Department of Veterans Affairs (VA) Medical Center, Manchester, NH; ${ }^{2}$ Department of Psychiatry, \\ Massachusetts General Hospital, Boston, MA; ${ }^{3}$ Harvard Medical School, Boston, MA; ${ }^{4}$ Department of Psychology, \\ University of Illinois at Urbana-Champaign, Urbana-Champaign, IL; ${ }^{5}$ Vietnam Era Twin Registry/Seattle Epidemi- \\ ologic Research and Information Center, VA Puget Sound Health Care System, Seattle, WA
}

\begin{abstract}
Two studies have reported decreased intensity dependence of the P2 event-related potential (ERP) in male combat veterans with posttraumatic stress disorder (PTSD), a response pattern presumed to reflect central nervous systeminduced protective inhibition and heightened central serotonergic activity. We used an identical twin, case-control design to investigate whether intensity dependence abnormalities reflect pretrauma vulnerability or are an acquired consequence of PTSD. ERPs were measured in male Vietnam combat veterans and their noncombat-exposed monozygotic twin brothers during a four-tone, stimulus-intensity modulation procedure. Contrary to previous findings in male veterans, the PTSD group had significantly steeper P2 amplitude intensity slopes, similar to those reported for female veterans and abused children with PTSD. Additionally, increased P2 amplitude intensity slope was associated with increased PTSD symptom severity, particularly the severity of reexperiencing symptoms. A mixed-model, random-effects analysis that included the combat-unexposed twins revealed a significant diagnosis by combat exposure interaction. Inspection of group means suggests that the observed increased P2 intensity dependence is a consequence of PTSD. Our findings further suggest that low serotonergic tone may emerge as one potential consequence of this disorder.
\end{abstract}

Key words: 5-HT, auditory intensity dependence, combat disorder, event-related potentials, posttraumatic, PTSD, rehabilitation, serotonin, stress disorders, twin studies.

\section{INTRODUCTION}

In 1990, Paige and colleagues published a seminal study applying event-related potential (ERP) methodology to the investigation of central nervous system function in posttraumatic stress disorder (PTSD) [1]. Using a four-tone, stimulus-intensity modulation (i.e., augmenting-reducing)

\footnotetext{
Abbreviations: $5-\mathrm{HT}=$ serotonin, 5 -HTTLPR $=$ 5-HT transporter gene, ANOVA $=$ analysis of variance, CAPS = Clinician-Administered PTSD Scale, EOG = electrooculogram, $\mathrm{ERP}=$ event-related potential, $\mathrm{ExP}+=$ combat-exposed twin with PTSD, ExP- = combat-exposed twin without PTSD, l = long, $\mathrm{MDD}=$ major depressive disorder, $\mathrm{PTSD}=$ posttraumatic stress disorder, $\mathrm{s}=$ short, SCL-90-R = Symptom Checklist-90Revised, SD = standard deviation, SSRI = selected serotonin reuptake inhibitor, $\mathrm{UxP}+=$ combat-unexposed cotwin of twin with PTSD, UxP- = combat-unexposed cotwin of twin without PTSD, VA = Department of Veterans Affairs, VET = Vietnam Era Twin (Registry).

*Dr. Metzger died February 9, 2008. Dr. Paige died April 14, 2004.

${ }^{\dagger}$ Address all correspondence to Scott P. Orr, PhD; Manchester VA Medical Center, Research Service (151), 718 Smyth Rd, Manchester, NH 03104; 603-624-4366, ext 6733; fax: 603-629-3265. Email: scott.orr@va.gov

DOI: 10.1682/JRRD.2007.07.0100
} 
paradigm [2], the investigators measured the slope of the function that related the amplitude of the P2 component to increasing sound intensity levels $(74,84,94$, and $104 \mathrm{~dB})$ in male Vietnam combat veterans with and without PTSD. Because PTSD is characterized by heightened nervous system sensitivity, Paige and colleagues proposed that veterans with PTSD would show a reduction in the amplitude of the P2 component at higher tone-intensity levels, producing a shallow amplitude intensity slope [1]. Termed "reducing" by early investigators [3], this ERP response pattern of decreased intensity dependence is believed to reflect a protectively tuned sensory system that protects the organism from sensory overload via a central gating mechanism. In contrast, the opposite pattern of increasing amplitudes in response to increasing stimulus intensities (i.e., "augmenting” or increased intensity dependence) has been linked to a cortex tuned to seek out increases in stimulus intensity. ${ }^{*}$ Supporting the interpretation of these ERP response profiles, studies have found that the temperament traits of extraversion [4] and novelty- [5] and sensation- [6-8] seeking are associated with increased intensity dependence.

Consistent with their predictions, Paige and colleagues found that Vietnam veterans with PTSD had significantly reduced P2 amplitude intensity slopes compared with veterans without PTSD [1]. This pattern of decreased intensity dependence was replicated in a second study of male Vietnam combat veterans [9], supporting the position that male Vietnam veterans with PTSD more readily enter a state of protective inhibition when presented with high-intensity stimuli.

Two studies of very different trauma samples, however, have reported increased, rather than decreased, intensity dependence abnormalities in PTSD. In a study of sexually and/or physically abused children, McPherson and colleagues found that children with PTSD (77\% female) had significantly steeper P2-N2 intensity dependence slopes than abused children without PTSD (50\% female) [10]. Metzger and colleagues also found increased P2 intensity dependence slopes in a study of

\footnotetext{
* "Intensity dependence" is a general term used to refer to the pattern of ERP amplitude changes to tones of increasing intensities. Some individuals show increased, and others decreased, intensity dependence. In addition to P2 amplitude, intensity dependence has been calculated from changes in N1 amplitude; P1-N1, N1-P2, and P2-N2 peak-to-peak amplitude; and tangential dipole source activity of the N1-P2 component.
}

female Vietnam nurse veterans with PTSD versus those without [11]. Moreover, increased P2 intensity dependence slope was associated with increased PTSD symptom severity. These findings suggest that some individuals with PTSD may be characterized by deficiencies in the cortical inhibitory system that protects against overstimulation.

Differences in sample characteristics such as trauma type, age, and/or sex may underlie the contrasting findings of decreased versus increased intensity dependence in PTSD. Methodological differences also exist between studies. Although Metzger et al. [11] employed a paradigm that closely paralleled the original study of Vietnam veterans [1], the paradigm and slope measurement used by McPherson and colleagues [10] differed considerably from those used in the studies of male combat veterans $[1,9]$. For example, the study by McPherson and colleagues used longer interstimulus intervals and employed a monetary incentive button-press task, whereas the remaining studies used a passive listening paradigm [10]. The McPherson et al. study also calculated slope from the change in the peak-to-peak amplitude between the P2 and N2 component across tone intensities [10].

The different intensity dependence findings in studies of PTSD may be attributable to less obvious sample characteristics. Specifically, increasing and divergent evidence has found that aberrantly strong or weak intensity dependence reflects inverse abnormalities in central serotonin (5-HT) transmission [12], one of the neurochemical systems believed to play a key role in the pathophysiology of PTSD [13]. Specifically, high intensity dependence appears to reflect low 5-HT neurotransmission in the primary auditory cortex, whereas low intensity dependence appears to reflect high 5-HT neurotransmission in this brain region. Support for this position comes from both animal $[5,14]$ and human research. Of greatest relevance are clinical findings linking disorders involving 5-HT dysfunction with intensity dependence. For example, increased intensity dependence has been observed in individuals with bipolar affective [6] and histrionic [15] disorders, fibromyalgia [16], and migraines [17-18]. Conversely, in addition to the findings from the two studies of male Vietnam veterans [1,9], decreased auditory intensity dependence has been reported in unipolar depressive [6] and generalized anxiety [19] disorders.

The report of decreased intensity dependence in generalized anxiety disorder [19] is of particular interest in light of Paige et al.'s finding of a correlation between P2 
amplitude intensity slope and anxiety but not PTSDrelated or depressive symptoms [1]. The finding of a link between anxiety and decreased intensity dependence is consistent with the belief that anxiety disorders are associated with hyperactivity of the 5-HT system [20]. Although the second intensity dependence study of male Vietnam combat veterans also found generally decreased intensity dependence in the PTSD group, secondary analyses revealed that PTSD patients with increased intensity dependence of both the P2 and N2 components had significantly more severe PTSD symptoms than PTSD patients with decreased P2 and N2 intensity dependence [9]. The notion that only some clinical patients will show distinct biological abnormalities (e.g., specific alterations in 5-HT regulation) has been discussed by Linka and colleagues in a study that found that intensity dependence abnormalities were limited to a subgroup of depressed patients [21]. The authors pointed out that such clinical heterogeneity is traditionally observed in genetic studies and most likely reflects clinical subtypes with genetic underpinnings. Thus, the observed heterogeneity in intensity dependence response patterns in the second study of male veterans and the opposite findings across studies of PTSD may represent biological, and potentially genetically based, PTSD subtypes.

More compelling evidence for an inverse link between 5-HT and intensity dependence comes from several studies demonstrating that increased intensity dependence assessed before treatment predicts a favorable response to selective serotonin reuptake inhibitors (SSRIs) in depressed individuals [22-24]. These findings additionally underscore Linka and colleagues' position of clinical heterogeneity, i.e., subgroups of depressed patients that respond to SSRI treatment versus those that do not [21]. In addition, some studies have found that acute tryptophan depletion decreased intensity dependence [25, cf 26]. Abstinent users of "ecstasy" (methylenedioxymethamphetamine), a drug shown to have neurotoxic effects on central serotoninergic systems in animal research, also show increased intensity dependence compared with control subjects [27-28]. An 18-month follow-up study also found that prior ecstasy use was associated with increased intensity dependence [29]. However, changes in ecstasy use at follow-up were not related to changes in intensity dependence, leading the researchers to speculate whether the increased intensity dependence exhibited by ecstasy users represents a preexisting trait or is an irreversible change in 5-HT function.
Finally, three studies examined the association between intensity dependence and genotypes associated with the transcriptional control region of the 5-HT transporter gene (5-HTTLPR). Two studies found that individuals with long (l) forms of the 5-HTTLPR genotype (or l/l genotype) demonstrated increased intensity dependence [30-31], whereas the third study found that individuals with the $1 / 1$ genotype demonstrated decreased intensity dependence [32]. The short (s) form of the 5-HTTLPR allele (or s allele) impairs gene transcription and reduces 5-HTTLPR levels and reuptake compared with the $1 / 1$ genotype [33], purportedly resulting in higher 5-HT availability. The presence of the 5-HTTLPR s allele has been associated with increased anxiety-related traits [33]. One study found that individuals with PTSD have a significantly higher frequency of the 5-HTTLPR s/s genotype than control subjects, suggesting that this genotype may be a genetic risk factor for PTSD [34]. Additionally, evidence shows that depressed patients with the 5-HTTLPR s/s genotype have poor treatment response to SSRIs [35]. In summary, divergent studies generally support intensity dependence as an indicator of central 5-HT neurotransmission and raise the possibility that the opposite intensity dependence findings in PTSD reflect biological subtypes of PTSD with potential genetic underpinnings related to 5-HT abnormalities (i.e., hyper- or hypofunction of 5-HT neurotransmission).

This study was conducted as part of a larger scale study of Vietnam combat veterans and their noncombatexposed, identical twins [36]. The goal of this study was twofold: (1) to replicate decreased P2 intensity dependence in male Vietnam combat veterans with PTSD and (2) to determine whether this biological abnormality represents a pretrauma vulnerability factor for PTSD following traumatic exposure or an acquired characteristic that develops after traumatic exposure. To this end, we used an identical twin, case-control design in which a nontrauma-exposed identical twin served as a surrogate for what the trauma-exposed person would be like in absence of the traumatic experience (e.g., pretrauma). Specifically, the non-trauma-exposed twin surrogate shares the genetic makeup of the trauma-exposed twin and much of the early developmental environment but not the effects of trauma. We investigated whether predicted P2 intensity dependence abnormalities found in combat veterans with PTSD would also be present in their identical cotwins who had not served in combat. The electrophysiological methodology in the present study is similar to 
that employed in the original study of male combat veterans [1] and identical to that used in the study of female Vietnam nurse veterans [11].

\section{METHODS}

\section{Participants}

The participants were drawn from a pool of male monozygotic twin pairs in which one twin served in combat in Vietnam while his cotwin did not and who both had participated in a previously described study of heart rate responses to loud tones [36]. A full description of the recruitment sources and strategy and the characteristics of the participant population has already been reported [36]. Exclusion criteria for twin pairs included the following in one or both members: (1) past, but not current, Vietnam-related PTSD; (2) current or past non-Vietnam related PTSD; and (3) current or past schizophrenic, paranoid, bipolar I, or other psychotic disorder. Single or both members of a twin pair were also excluded if they used psychotropic or other potentially confounding medications or substances during the month prior to testing. We found it necessary to include nonmedicated singletons in order to maintain statistical power in this rare and unique sample. For tests of the origin of P2 amplitude intensity slope abnormalities, a statistical approach was used that is capable of handling missing data in one member of a twin pair (see "Statistical Analysis" section, p. 441).

All participants completed psychodiagnostic and psychometric testing and the four-tone intensity dependence paradigm used in previous studies [1,11]. This research protocol was approved by the institutional review board of the Manchester Department of Veterans Affairs Medical Center in New Hampshire. Written informed consent was obtained from each participant after the procedures had been fully explained.

\section{Psychodiagnostics and Psychometrics}

The Clinician-Administered PTSD Scale (CAPS): Current and Lifetime Diagnosis Version was administered to determine the presence or absence of combatrelated PTSD in the combat-exposed twins [37]. Psychometrics included an 18-item Combat Severity Scale [38] and the Symptom Checklist-90-Revised (SCL-90-R) [39].

\section{Procedure}

Testing occurred between 7:00 am and 3:00 pm in a sound-attenuated room connected via wires to an adjoining portion of the laboratory in which the experimental apparatus was located. Participants were seated upright in a comfortable armchair. Prior to the recordings, participants' hearing threshold for $1,000 \mathrm{~Hz}$ tones we estimated using a $5 \mathrm{~dB}$ descending and ascending staircase method. We recorded electroencephalogram activity from the midline sites (Fz, Cz, and Pz; 10-20 system) [40] using tin electrodes embedded in a nylon cap (Electro-Cap International; Eaton, Ohio), referenced to linked earlobes, and grounded at the forehead. Electrooculogram (EOG) activity was recorded at the outer canthus and infraorbitally to the left eye. Impedances were kept below $5 \mathrm{k} \Omega$. We amplified signals with a bandpass of 0.1 to $150 \mathrm{~Hz}$ using Coulbourn high-gain bioamplifiers (Whitehall, Pennsylvania) and sampled the data at a rate of $1,000 \mathrm{~Hz}$ using a NeuroScan system with a resolution of $.049 \mathrm{~V} / \mathrm{bit}$ (Charlotte, North Carolina) from $100 \mathrm{~ms}$ pre- to $500 \mathrm{~ms}$ poststimulus onset. Trials with excessive eye-movement artifact (EOG range $\pm 85 \mu \mathrm{V}$ ) were excluded. Prior to averaging waveforms, we digitally filtered the signals at 0.1 to $14 \mathrm{~Hz}$ (12 dB/octave). We determined peak and latency measures for P2 components using a NeuroScan automated scoring program. Selected peaks were verified by visual inspection. All auditory stimuli were generated by STIM software (NeuroScan) and were presented binaurally over E-A-RTONE (Aearo Company; Indianapolis, Indiana) insert earphones. As in previous studies, the stimuli consisted of $500 \mathrm{~ms}$ of $780 \mathrm{~Hz}$ tones gated with rise and fall times of $25 \mathrm{~ms}$ [1,11]. The tones were presented at 4 intensities $(74,84,94$, and $104 \mathrm{~dB}$ sound pressure level) in 4 blocks of 16 tones, repeated 4 times in a Latin square design for a total of 256 tone presentations. The interstimulus interval ranged from 2 to $4 \mathrm{~s}$, with a mean interval of $3 \mathrm{~s}$. The procedure lasted approximately $13 \mathrm{~min}$ utes. All participants received the following instructions:

In this session you will hear a series of tones. The tones will vary in loudness from soft to very loud. You do not have to respond to the tones, but you should stay alert and pay attention to the tones while remaining relaxed. We ask that you try to keep your body and especially your eyes as still as possible. Try not to blink your eyes immediately before, during, and immediately after the tones. In between the tones you will have a couple of seconds to blink before the next tone. Again, we have placed a cross in front of you as a place to focus your eyes. Use the cross as a 
place to look to help keep your eyes from wandering. Do you have any questions?

P2 peak amplitude and latency measures were determined at the $\mathrm{Cz}$ site from each participant's averaged waveforms for each stimulus intensity. P2 was defined as the most positive point between 140 and $230 \mathrm{~ms}$ poststimulus onset relative to the $100 \mathrm{~ms}$ prestimulus baseline.

\section{Statistical Analysis}

The design included two factors. Twin pairs were classified according to the combat-exposed twin's PTSD diagnosis, viz current combat-related PTSD or non- (i.e., never had) combat-related PTSD. Each pair contained two exposure levels: combat-exposed and non-combatexposed. Thus, four participant groups were included: combat-exposed twin with PTSD $(\mathrm{ExP}+)(n=14)$, combat-exposed twin without PTSD (ExP-) $(n=35)$, (highrisk) combat-unexposed cotwin of twin with PTSD (UxP+) $(n=22)$, and (low-risk) combat-unexposed cotwin of twin without PTSD (UxP-) $(n=35)$.

To test whether results obtained in the combat veterans replicated earlier findings, we performed a two-tailed $t$-test on the P2 amplitude intensity slope between the $\mathrm{ExP}+$ and ExP- groups. P2 amplitude intensity slope was calculated as the slope of the regression line for the P2 component peak amplitude across the four tones of increasing intensity. Group differences in P2 amplitudes and latencies were also examined with separate two-factor repeated measures analyses of variance (ANOVAs) with group (ExP+, ExP-) as a between-subjects factor and stimulus intensity $(74,84,94$, and $104 \mathrm{~dB}$ tones) as the repeated measure. Statistical probabilities for the effects involving repeated measures were corrected with the Geisser-Greenhouse procedure. To determine the degree to which intensity dependence and absolute response magnitude were associated with the demographic variables and measures of PTSD severity and general psychopathology in the combat-exposed twins, we computed Pearson correlations among these measures.

Finally, to examine the origin of potential group differences in $\mathrm{P} 2$ amplitude intensity slope in the ExP+ versus ExP- participants, we analyzed the data from all four groups by means of a mixed model, with diagnosis as a between-pairs fixed effect, exposure as a within-pairs fixed effect (repeated measure), and pairs as a random effect [41]. Because the mixed model is capable of handling missing data in one member of a twin pair, we retained the data from singletons to yield maximum power. This model provides a $t$ statistic for each main effect and the interaction. If a dependent variable represents a vulnerability factor for PTSD, the model predicts a significant diagnosis main effect. If, on the other hand, a dependent variable represents an acquired PTSD sign, the model predicts a significant diagnosis $\times$ combat exposure interaction.

\section{RESULTS}

\section{Demographic and Psychometric Data}

Group mean and standard deviation (SD) values for demographic and psychometric data are presented in Table 1. As is common, the results of $t$-test comparisons indicated that the ExP+ group was significantly younger $\left(t_{(43)}=2.2, p=0.04\right)$ and reported greater combat exposure $\left(t_{(43)}=-4.2, p<0.001\right)$ than the ExP- group. As expected, the ExP+ group had significantly higher CAPS Total $\left(t_{(43)}=-4.2, p<0.001\right)$ and SCL-90-R General Severity Index $\left(t_{(43)}=-4.6, p<0.001\right)$, depression subscale $\left(t_{(43)}=-3.8, p<0.001\right)$, and anxiety subscale $\left(t_{(42)}=\right.$ $-4.2, p<0.001)$ scores. All participants had a hearing threshold $\leq 40 \mathrm{~dB}$.

\section{Electrophysiological Data}

Averaged waveforms for eight participants $(\mathrm{ExP}+=$ 2 , $\mathrm{UxP}_{+}=1, \mathrm{ExP}-=2$, UxP- $=3$ ) contained 10 single artifact-free trials. These participants' data were not scored and were excluded from analyses. Separate one-way ANOVAs with group (Exp+, $\left.\mathrm{UxP}^{+}, \mathrm{ExP}-, \mathrm{UxP}_{-}\right)$as the between-subjects factor indicated that the groups did not differ in the number of artifact-free trials retained for the averaged waveforms for any of the tone intensity levels (all $F_{(3,97)}<1.1, p>0.35$; see Table 1 for group mean values).

Contrary to the prediction of decreased intensity dependence for male combat veterans with PTSD, examination of group mean values revealed increased, rather than decreased, P2 amplitude intensity slopes in the $\mathrm{ExP}+$ compared with the ExP- group. Results of a $t$-test comparison for the ExP+ versus ExP- group confirmed that this difference was statistically significant $\left(t_{(43)}=\right.$ $-2.2, p=0.03)$. Interestingly, the pattern of increased $\mathrm{P} 2$ amplitude intensity slopes observed in the present sample of combat veterans with PTSD is strikingly similar to that reported in our previous study of female Vietnam nurse veterans with PTSD [11] (Figures 1 and 2). Additionally, the repeated measures ANOVA for P2 amplitude revealed a significant main effect for stimulus $\left(F_{(3,129)}=53.0, p<\right.$ $0.001)$ and a significant diagnosis $\times$ stimulus interaction 
JRRD, Volume 45, Number 3, 2008

Table 1.

Group mean \pm standard deviation demographic, psychometric, and dependent measures for posttraumatic stress disorder (PTSD) and non-PTSD combat-exposed and combat-unexposed twin pairs.

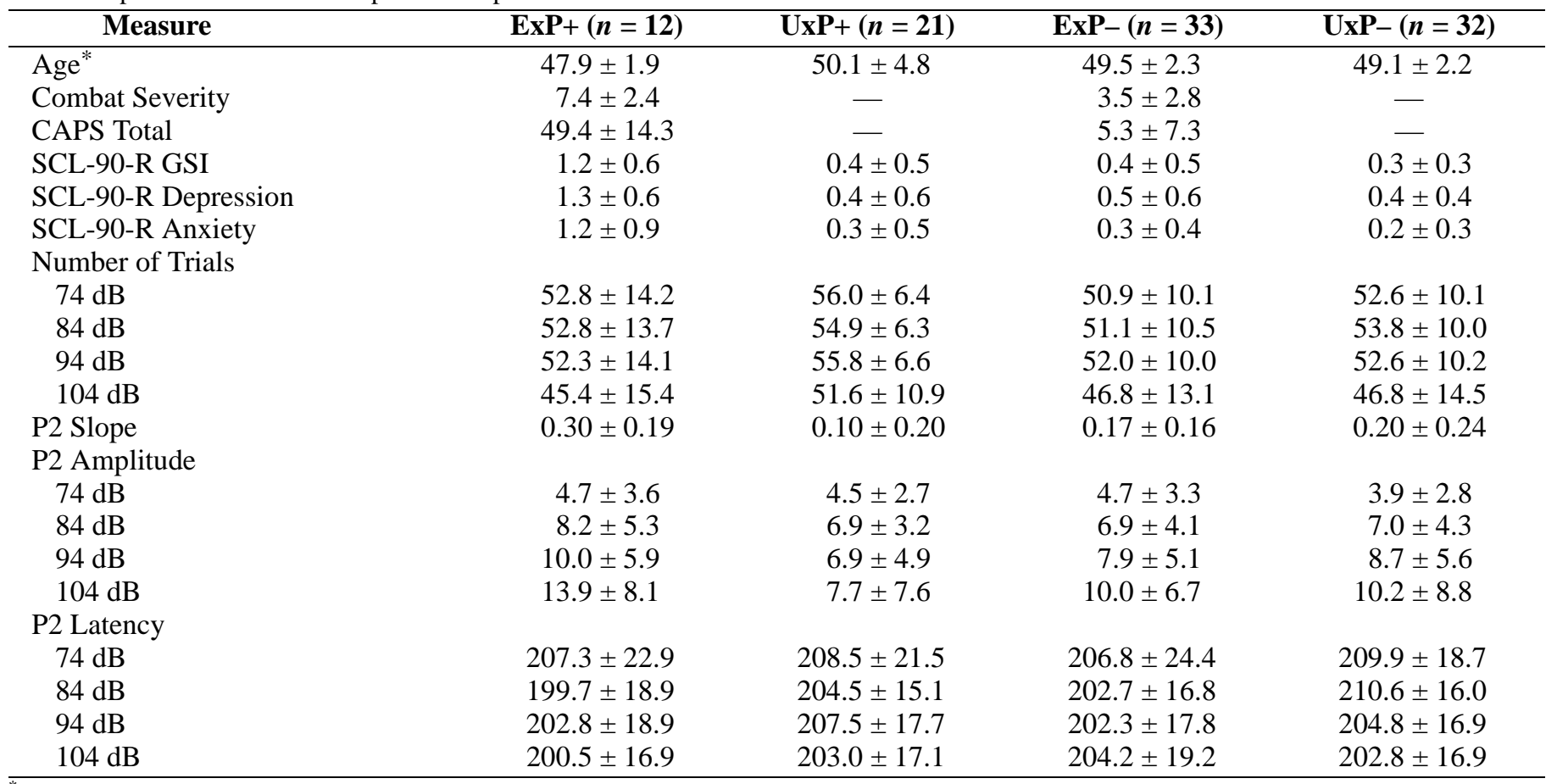

*Age as of October 1, 1997.

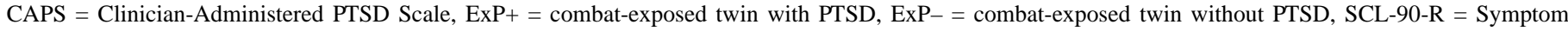

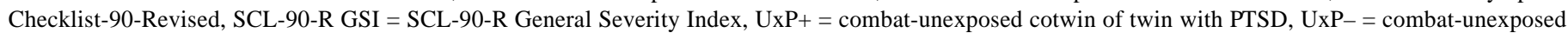
cotwin of twin without PTSD.

$\left(F_{(3,129)}=3.8, p=0.04\right)$ but no main effect for diagnosis $\left(F_{(1,43)}=1.3, p=0.26\right)$. Follow-up t-test comparisons indicated that the groups did not significantly differ in $\mathrm{P} 2$ amplitude to the $74 \mathrm{~dB}\left(t_{(43)}=0.0 p=0.99\right), 84 \mathrm{~dB}\left(t_{(43)}=\right.$ $-1.0, p=0.37), 94 \mathrm{~dB}\left(t_{(43)}=-1.2, p=0.24\right)$, or $104 \mathrm{~dB}$ $\left(t_{(43)}=-1.6, p=0.11\right)$ tone. Examination of P2 latency revealed neither a diagnosis $\left(F_{(1,43)}<1\right)$ nor a stimulus $\left(F_{(3,129)}=1.5, p=0.23\right)$ main effect nor a diagnosis $\times$ stimulus interaction $\left(F_{(3,129}<1\right){ }^{*}$

\footnotetext{
*Peak N1 amplitude and latency (defined as the largest negative component measured at $\mathrm{Cz}$ between 80 and $140 \mathrm{~ms}$ poststimulus) for each tone intensity and $\mathrm{N} 1$ amplitude intensity slopes were calculated and examined following the strategy employed for the P2 component. Separate two-factor repeated measures ANOVAs for N1 amplitude and latency with group (ExP+, ExP-) as a between-subjects factor and stimulus intensity $(74,84,94$, and $104 \mathrm{~dB}$ tones) as the repeated measure indicated no significant main effects for group or group $\times$ stimulus interaction (all $p>0.48$ ). We also found no ExP+ versus $\mathrm{ExP}$ - group difference for $\mathrm{N} 1$ amplitude intensity slope $\left(t_{(43)}=0.5\right.$, $p=0.62)$.
}

Pearson correlations revealed that increased P2 amplitude intensity slopes were related to higher combat exposure, CAPS Total, and reexperiencing symptoms severity scores in the combat-exposed veterans (Table 2). Interestingly, P2 amplitude intensity slopes were not significantly related to the remaining PTSD symptom cluster scores or the SCL-90-R general psychopathology, anxiety, or depression subscale scores. Higher combat-exposure scores, but not CAPS Total or subscale scores, were also related to increased P2 amplitude to the 84, 94, and 104 $\mathrm{dB}$ tones. Age was not related to any of the electrophysiological measures.

In order to assess whether age and combat exposure are problematic confounds for interpreting the group difference in P2 amplitude intensity slope, we performed separate analyses of covariance using these variables as covariates. The group difference in P2 amplitude intensity slope remained significant $\left(F_{(1,42)}=4.1, p<0.05\right)$ when age was included as a covariate. However, the group difference disappeared $\left(F_{(1,42)}<1\right)$ when combatexposure score was included as the covariate. This latter 


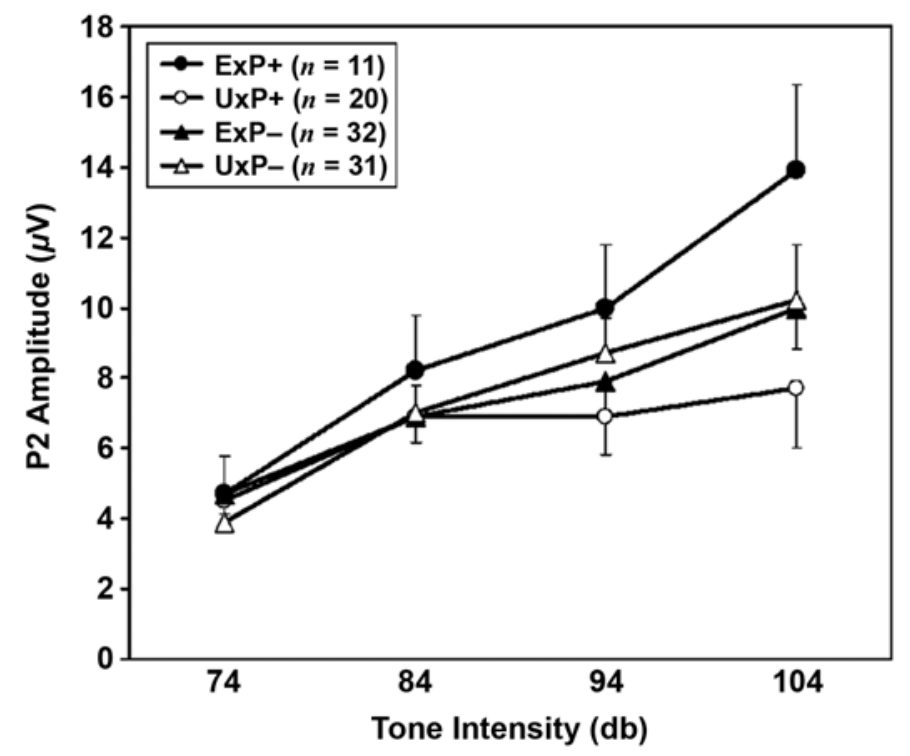

Figure 1.

Mean and standard error for P2 amplitudes measured at Cz, plotted as function of tone intensity for combat-exposed twin with posttraumatic stress disorder (PTSD) (ExP+), combat-exposed twin without PTSD (ExP-), combat-unexposed cotwin of twin with PTSD (UxP+), and combat-unexposed cotwin of twin without PTSD (UxP-).

result makes it impossible to rule out the effects of combat exposure on P2 amplitude intensity slope since it indicates that the variance shared between combat exposure and P2 amplitude intensity slope overlaps substantially with the variance shared between having PTSD and P2 amplitude intensity slope [42]. CAPS Total and combat-exposure scores were also significantly related $(r=$ $0.56, p<0.001$ ).

Because increased P2 slopes have been reported in depressed patients who responded favorably to antidepressants [22-24], the group difference in mean P2 amplitude intensity slope was reexamined following the removal of one participant in the ExP+ group who had concurrent PTSD and major depressive disorder (MDD). The comparison between the ExP+ subgroup without the subject with MDD (mean $\pm \mathrm{SD}=0.31 \pm 0.20$ ) and the ExP- group (mean $\pm \mathrm{SD}=0.17 \pm 0.16)$ remained significant $\left(t_{(42)}=\right.$ $-2.3, p=0.02)$.

We then performed a mixed-model analysis using the data from both the combat-exposed and -unexposed twin members to determine the likely origin for the finding of increased intensity dependence in this PTSD sample. The results indicated no main effect for exposure $(t=0.4, p=$

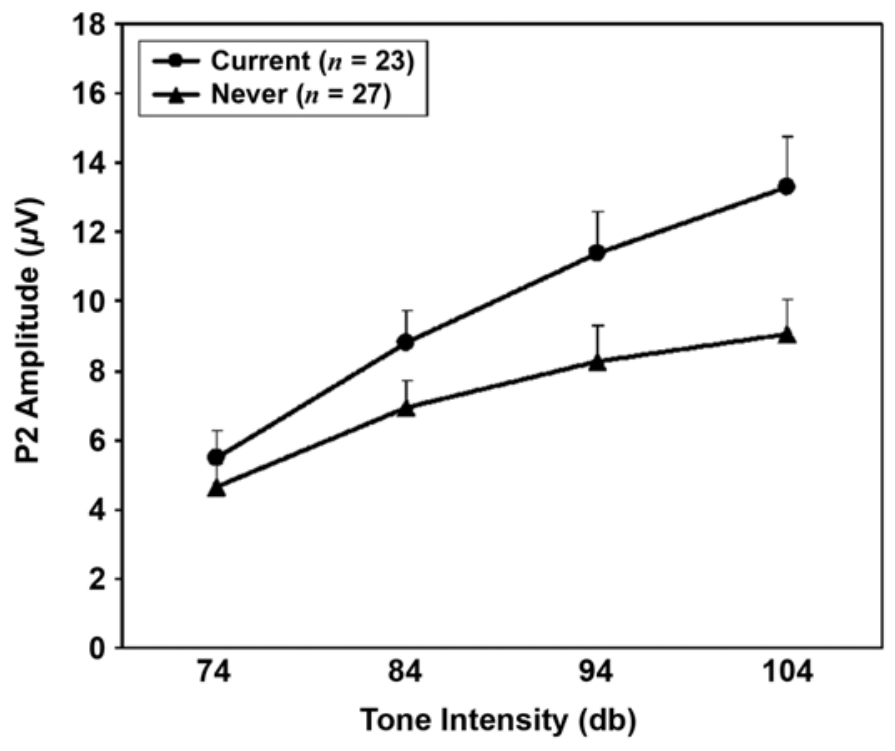

Figure 2.

Mean and standard error P2 amplitudes measured at CZ, plotted as function of tone intensity for female Vietnam nurse veterans with current posttraumatic stress disorder (PTSD) and those who never had PTSD. Source: Adapted from Metzger LJ, Carson MA, Paulus LA, Lasko NB, Paige SR, Pitman RK, Orr SP. Event-related potentials to auditory stimuli in female Vietnam nurse veterans with posttraumatic stress disorder. Psychophysiology. 2002;39(1):49-63. [PMID: 12206295]

0.70 ) but a near significant main effect for diagnosis ( $t=$ $1.9, p<0.06$ ), modified by a significant diagnosis $\times$ combat exposure interaction $(t=3.0, p=0.004)$. Examination of the pattern of mean P2 amplitude intensity slopes (Table 1, Figure 1) reveals very different patterns of intensity dependence in the $\mathrm{ExP}+$ and $\mathrm{UxP}+$ groups, with the UxP+ group having a shallower $\mathrm{P} 2$ amplitude intensity dependence slope than both the ExP- and UxPgroups. A $t$-test indicated a trend for shallower $\mathrm{P} 2$ slopes in the $\mathrm{UxP}+$ group compared with the ExP- and UxPgroups combined $\left(t_{(84)}=1.8, p=0.08\right)$. As a more conservative test, we repeated the mixed-model analysis in a subgroup in which data were present for both members of the twin pairs (i.e., excluding singletons). The diagnosis $\times$ combat exposure interaction remained significant $(t=$ $2.2, p=0.04$ ). Additionally, a dependent $t$-test (twotailed) revealed a nearly significant higher P2 amplitude intensity slope in the ExP+ compared with the UxP+ despite very limited power $\left(t_{(6)}=2.3, p=0.06\right)$.

Figure 3 shows scatter plots of P2 amplitude intensity slopes separately for each group. Notably, the ExP+ group contains no members with a negative P2 amplitude 
JRRD, Volume 45, Number 3, 2008

Table 2.

Pearson correlation coefficients for dependent measures and demographic, posttraumatic stress disorder (PTSD), and general psychopathology severity measures in PTSD and non-PTSD combat-exposed veterans $(n=45)$.

\begin{tabular}{lccccccccc}
\hline Variable & Age & $\begin{array}{c}\text { Combat } \\
\text { Severity }\end{array}$ & CAPS Total & $\begin{array}{c}\text { CAPS } \\
\text { Reexp }\end{array}$ & $\begin{array}{c}\text { CAPS } \\
\text { A/N }\end{array}$ & $\begin{array}{c}\text { CAPS } \\
\text { Arousal }\end{array}$ & $\begin{array}{r}\text { SCL-90-R } \\
\text { GSI }\end{array}$ & $\begin{array}{c}\text { SCL-90-R } \\
\text { DEP }\end{array}$ & $\begin{array}{c}\text { SCL-90-R } \\
\text { Anxiety }\end{array}$ \\
\hline P2 Slope & -0.14 & $0.38^{*}$ & $0.31^{\dagger}$ & $0.35^{\dagger}$ & 0.28 & 0.23 & 0.17 & 0.14 & 0.24 \\
P2 Amplitude & & & & & & & & & \\
$74 \mathrm{~dB}$ & 0.03 & 0.15 & -0.14 & -0.11 & -0.12 & -0.18 & -0.22 & -0.22 & -0.17 \\
$84 \mathrm{~dB}$ & -0.05 & $0.34^{\dagger}$ & -0.01 & 0.03 & 0.01 & -0.10 & -0.06 & -0.03 & 0.02 \\
$94 \mathrm{~dB}$ & -0.06 & $0.33^{\dagger}$ & 0.05 & 0.09 & 0.05 & 0.00 & -0.03 & -0.01 & 0.06 \\
$104 \mathrm{~dB}$ & -0.09 & $0.37^{\dagger}$ & 0.17 & 0.21 & 0.16 & 0.09 & 0.03 & 0.02 & 0.11 \\
\hline \hline
\end{tabular}

${ }^{*} p<0.01$.

${ }^{\dagger} p<0.05$.

A/N = Avoidance/Numbing subscale, CAPS = Clinician-Administered PTSD Scale, DEP = Depression subscale, GSI = General Severity Index , Reexp = Reexperiencing subscale, SCL-90-R = Symptom Checklist-90-Revised.

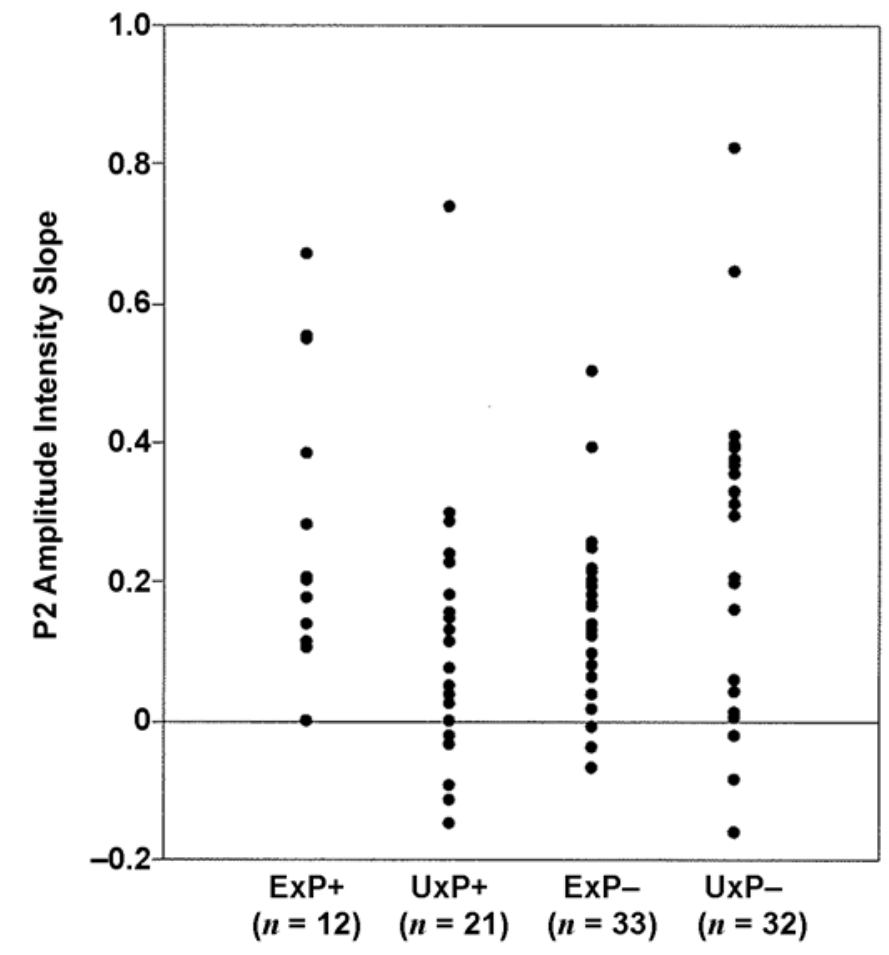

Figure 3.

Scatter plots of P2 amplitude intensity slopes for combat-exposed twin with posttraumatic stress disorder (PTSD) (ExP+), combatexposed twin without PTSD (ExP-), combat-unexposed cotwin of twin with PTSD $(\mathrm{UxP}+)$, and combat-unexposed cotwin of twin without PTSD (UxP-).

intensity slope, whereas 38 percent of the UxP+ group members have a negative slope; 9 percent of the ExPand 25 percent of $\mathrm{UxP}$ - group members have a negative P2 amplitude intensity slope.

\section{DISCUSSION}

Our results did not replicate findings of decreased P2 amplitude intensity slopes in male combat veterans with PTSD [1,9]. Rather, male veterans with PTSD had significantly steeper P2 amplitude intensity slopes, much like those reported in our previous study of female Vietnam nurse veterans [11] and in the study of abused children with PTSD [10]. These findings suggest that the observed heightened intensity dependence in PTSD is not sex, age, or trauma specific. Similar to our findings in female Vietnam nurse veterans [11], increased P2 amplitude intensity slope was associated with increased PTSD symptom severity. Additionally, the strongest correlation with PTSD symptoms was between P2 amplitude intensity slope and reexperiencing, the symptom cluster most unique to PTSD. This observation, in conjunction with the relative absence of comorbid depression and the absence of a relationship between P2 amplitude intensity slopes and measures of depression, anxiety, or general psychopathology, suggests that the increased intensity dependence reflects a feature related to the presence of PTSD in this sample, rather than depression, anxiety, or psychopathology in general.

Our study is unable to resolve the role of combat exposure in the finding of increased P2 amplitude intensity slopes in combat veterans with PTSD versus those without. Using combat-exposure scores as a covariate eliminated group differences in P2 amplitude intensity slopes. For combat exposure to be confounded with PTSD diagnosis in research with combat veterans is not uncommon; past studies have similarly reported a significant positive relationship between combat-exposure scores 
and PTSD symptom severity [43-45]. However, contrary to the common assumption that greater trauma exposure might produce more severe PTSD, findings from one study suggest that the causal relationship might be reversed. In a 14-year test-retest study measuring combat exposure in a large sample of Vietnam veterans, Koenen and colleagues found that changes in the severity of combat-exposure scores were related to changes in PTSD symptom severity, particularly the severity of reexperiencing symptoms [45]. These findings suggest that the association between a higher degree of self-reported combat exposure and PTSD symptom severity may be to some extent driven by a reporting bias associated with PTSD reexperiencing symptoms. This raises the question of whether a more objective measure of combat exposure would similarly confound P2 amplitude intensity slope findings.

The reason previous studies of male Vietnam combat veterans with PTSD found decreased P2 amplitude intensity slopes remains unclear [1,9]; the current study found the opposite pattern. These opposite findings may be due to differences in laboratory procedures or samples. For example, tone intensity levels, which were not identical across studies, are known to impact the linear regression slopes, with very high sound intensities $(>100 \mathrm{~dB})$ leading to a reduction in the ERP response [46]. Four of the five intensity dependence studies in PTSD used tone levels above $100 \mathrm{~dB}$. However, three of these studies found increased, as opposed to decreased, P2 amplitudes at the highest intensity levels in individuals with PTSD. Only the study by Paige and colleagues found decreased P2 intensity in subjects with PTSD to the highest tone intensity (i.e., $104 \mathrm{db}$ ) [1], which was also employed in the current study and our study of female nurse veterans [11]. Therefore, differences in tone intensities remain an unlikely explanation for the divergent findings in PTSD.

The contrasting intensity dependence findings in combat veterans may be related to differences in the nature of their traumatic exposure (e.g., witnessing injury and death vs fear of their own death), phase of illness, or treatment history. The opposing intensity dependence response patterns might also reflect biological subtypes of PTSD, distinguished by the severity or dominance of different symptom profiles (i.e., re experiencing vs anxiety symptoms). As previously discussed, decreased P2 amplitude intensity dependence was associated with increased anxiety symptoms in one study of male combat veterans [1], whereas increased P2 amplitude intensity dependence was associated with increased PTSD symptom severity in a sample of female Vietnam nurse veterans [11] and increased severity of PTSD and reexperiencing symptoms in the current sample of male combat veterans. Furthermore, as discussed in the "Introduction," the biological underpinning of these hypothetical subtypes may be specific alterations in the 5-HT system (e.g., hyper- or hypofunction of 5-HT neurotransmission). Although other neurochemical systems (e.g., dopamine, acetylcholine) have been implicated in the modulation of intensity dependence response patterns (e.g., Strobel et al. [31]), the most consistent evidence supports central 5-HT as the key neuromodulator [12], with low 5-HT neurotransmission associated with increased intensity dependence and high 5-HT neurotransmission with decreased intensity dependence. Within this framework, decreased intensity dependence (reflecting high 5-HT tone) may characterize a subtype of PTSD dominated by anxiety and avoidance symptoms, behaviors associated with the overstimulation of postsynaptic 5-HT2 receptors [47]. Conversely, increased intensity dependence (reflecting low 5-HT tone) may characterize a subtype of PTSD dominated by reexperiencing symptoms. Specifically, 5-HT has been shown to have an inhibitory influence on norepinephrine [48], the neurochemical believed to underlie reexperiencing symptoms in PTSD [13]. Without the appropriate levels of 5-HT, individuals with PTSD might become more susceptible to the resurgence of trauma-related memories. However, regardless of the etiological basis for the opposite intensity dependence findings in PTSD, P2 amplitude intensity slope appears to offer a promising clinical tool. As with studies of depressed patients [1921], future investigations are needed to determine whether increased intensity dependence can provide a prognostic indicator of individuals with PTSD who are most likely to show a positive treatment response to SSRIs, ultimately facilitating treatment selection and process in individuals with PTSD.

Although our findings represent a failed replication of decreased amplitude intensity in male Vietnam combat veterans, the novel and unique contribution of this work lies in the findings of the identical cotwins who had not served in combat. The P2 amplitude intensity slopes of the cotwins of combat veterans without PTSD were very similar to their combat-exposed brothers, suggesting that combat exposure alone does not affect P2 amplitude intensity slope. Conversely, the P2 amplitude intensity slope of the cotwins of combat veterans with PTSD were quite different, with the combat-exposed cotwins with 
PTSD showing steeper, and their combat unexposed cotwins without PTSD showing shallower, P2 amplitude intensity slopes relative to the non-PTSD twin pairs. The significant diagnosis $\times$ combat exposure interaction produced by the mixed-model analysis supports the conclusion that the increased intensity dependence in this sample of male veterans with PTSD was an acquired condition and not a preexisting vulnerability marker for PTSD. Additionally, we found a statistical trend for somewhat shallower P2 amplitude intensity slopes in the unexposed cotwins of veterans with PTSD compared with the combat-exposed veterans without PTSD and their unexposed cotwins, with the UxP+ group containing the highest percentage of participants with a negative P2 amplitude intensity slope. We must also note that no main effect was found for combat exposure. This result suggests that combat exposure in and of itself is not associated with increased intensity dependence.

It is possible that reduced P2 amplitude intensity slope, and hypothetically higher 5-HT tone, in the unexposed cotwins of veterans with PTSD represents a vulnerability marker for PTSD and potential phenotypic expression of genetic risk (e.g., the 5-HTTLPR s/s genotype) for this disorder. Furthermore, the finding that the trauma-exposed cotwins with PTSD showed the opposite intensity dependence pattern suggests that the biological underpinning is somehow modified (i.e., from high to low 5-HT tone) with traumatic exposure and the development of this disorder. These conclusions, however, must remain speculative given they are based on a small sample and a statistical trend.

\section{CONCLUSIONS}

In summary, we examined P2 amplitude intensity slopes in male combat Vietnam veterans and their combat-unexposed identical cotwins. Contrary to findings of decreased P2 amplitude intensity slopes reported in previous studies of male combat veterans with PTSD [1,9], we found increased P2 amplitude intensity slopes, similar to those reported for female veterans [11] and abused children [10] with PTSD. Additionally, mixed-model, random-effects analysis including the combat-unexposed twins revealed a significant diagnosis $\times$ combat exposure interaction. Inspection of group mean values suggests that the observed increased intensity dependence in male combat veterans with PTSD is a consequence of this disorder. Findings suggest that low serotonergic tone may emerge as one potential consequence of PTSD. Future studies should investigate the clinical usefulness of assessing pretreatment P2 amplitude intensity slope, potentially in conjunction with identification of the 5-HTTLPR genotype, for predicting individuals with PTSD who are most likely to show a favorable response to SSRI treatment.

\section{ACKNOWLEDGMENTS}

We would like to thank Heike Croteau and Dr. Mark Lasko for technical assistance. Additional Harvard/ Department of Veterans Affairs (VA) PTSD Twin Study Investigators include Seth A. Eisen, MD; Mark W. Gilbertson, PhD; Gregory M. Gillette, MD; Jack Goldberg, PhD; Tamara V. Gurvits, MD, PhD; William G. Henderson, PhD; Terence M. Keane, PhD; Michael J. Lyons, PhD; Arieh Y. Shalev, MD; William R. True, PhD; Ming T. Tsuang, MD, PhD; Frank W. Weathers, PhD; and Rachel Yehuda, PhD.

The VA provided financial support for the development and maintenance of the Vietnam Era Twin (VET) Registry. Through their support of the VET Registry, numerous organizations provided invaluable assistance, including the Department of Defense; National Personnel Records Center, National Archives and Records Administration; Internal Revenue Service; National Institutes of Health; National Opinion Research Center; National Research Council, National Academy of Sciences; and Institute for Survey Research, Temple University. We also gratefully acknowledge the continued cooperation and participation of the members of the VET Registry and their families. Without their contribution, this research would not have been possible.

This article is dedicated to the memories of Dr. Stephen R. Paige, the coauthor who conceived the study of P2 amplitude intensity slope within the Harvard/VA Medical Center Twin Study of Biologic Markers in PTSD, and Dr. Linda J. Metzger, the coauthor who oversaw the conduct of this study, performed the data analyses, and took the lead in preparing and finalizing the manuscript.

This material was based on work supported by the U.S. Public Health Service (grant MH54636) and the National Health and Medical Research Council (grant 300403).

The authors have declared that no competing interests exist. 


\section{REFERENCES}

1. Paige SR, Reid GM, Allen MG, Newton JE. Psychophysiological correlates of posttraumatic stress disorder in Vietnam veterans. Biol Psychiatry. 1990;27(4):419-30. [PMID: 2310797]

2. Buchsbaum MS, Stevens SS. Neural events and psychophysical law. Science. 1971;172(982):502. [PMID: 5550509]

3. Buchsbaum MS, Silverman J. Stimulus intensity control and the cortical evoked response. Psychosom Med. 1968; 30(1):12-22. [PMID: 5640282]

4. Friedman J, Meares R. Cortical evoked potentials and extraversion. Psychosom Med. 1979;41(4):279-86. [PMID: 482524]

5. Juckel G, Molnár M, Hegerl U, Csépe V, Karmos G. Auditory-evoked potentials as indicator of brain serotonergic activity-First evidence in behaving cats. Biol Psychiatry. 1997;41(12):1181-95. [PMID: 9171909]

6. Brocke B, Beauducel A, John R, Debener S, Heilemann H. Sensation seeking and affective disorders: Characteristics in the intensity dependence of acoustic evoked potentials. Neuropsychobiology. 2000;41(1):24-30. [PMID: 10629432]

7. Zuckerman M. The psychophysiology of sensation seeking. J Pers. 1990;58(1):313-45. [PMID: 2198341]

8. Hegerl U, Karnauchow I, Herrmann WM, Müller-Oerlinghausen B. Intensity dependence of auditory evoked N1/P2 component and personality. Neuropsychobiology. 1992;26(3): 166-72. [PMID: 1294896]

9. Lewine JD, Thoma RJ, Provencal SL, Edgar C, Miller GA, Canive JM. Abnormal stimulus-response intensity functions in posttraumatic stress disorder: An electrophysiological investigation. Am J Psychiatry. 2002;159(10):1689-95. [PMID: 12359674]

10. McPherson WB, Newton JE, Ackerman P, Oglesby DM, Dykman RA. An event-related brain potential investigation of PTSD and PTSD symptoms in abused children. Integr Physiol Behav Sci. 1997;32(1):31-42. [PMID: 9105912]

11. Metzger LJ, Carson MA, Paulus LA, Lasko NB, Paige SR, Pitman RK, Orr SP. Event-related potentials to auditory stimuli in female Vietnam nurse veterans with posttraumatic stress disorder. Psychophysiology. 2002;39(1):49-63. [PMID: 12206295]

12. Hegerl U, Juckel G. Intensity dependence of auditory evoked potentials as an indicator of central serotonergic neurotransmission: A new hypothesis. Biol Psychiatry. 1993; 33(3):173-87. [PMID: 8383545$]$

13. Davis LL, Suris A, Lambert MT, Heimberg C, Petty F. Post-traumatic stress disorder and serotonin: New directions for research and treatment. J Psychiatry Neurosci. 1997; 22(5):318-26. [PMID: 9401312]
14. Juckel G, Hegerl U, Molnár M, Csépe V, Karmos G. Auditory evoked potentials reflect serotonergic neuronal activity-A study in behaving cats administered drugs acting on 5-HT1A autoreceptors in the dorsal raphe nucleus. Neuropsychopharmacology. 1999;21(6):710-16. [PMID: 10633476$]$

15. Wang W, Wang Y, Fu X, Liu J, He C, Dong Y, Livesley WJ, Jang KL. Cerebral information processing in personality disorders: I. Intensity dependence of auditory evoked potentials. Psychiatry Res. 2006;141(2):173-83.

[PMID: 16499979]

16. Carrillo-de-la-Peña MT, Vallet M, Pérez MI, GómezPerretta C. Intensity dependence of auditory-evoked cortical potentials in fibromyalgia patients: A test of the generalized hypervigilance hypothesis. J Pain. 2006;7(7):480-87. [PMID: 16814687]

17. Siniatchkin M, Kropp P, Neumann M, Gerber W, Stephani $\mathrm{U}$. Intensity dependence of auditory evoked cortical potentials in migraine families. Pain. 2000;85(1-2):247-54.

[PMID: 10692625]

18. Wang W, Timsit-Berthier M, Schoenen J. Intensity dependence of auditory evoked potentials is pronounced in migraine: An indication of cortical potentiation and low serotonergic neurotransmission? Neurology. 1996;46(5):1404-9.

[PMID: 8628490]

19. Senkowski D, Linden M, Zubrägel, Bär T, Gallinat J. Evidence for disturbed cortical signal processing and altered serotonergic neurotransmission in generalized anxiety disorder. Biol Psychiatry. 2003;53(4):304-14.

[PMID: 12586449]

20. Eison MS. Serotonin: A common neurobiologic substrate in anxiety and depression. J Clin Psychopharmacol. 1990; 10(3 Suppl):26S-30S. [PMID: 2198299]

21. Linka T, Sartory G, Bender S, Gastpar M, Müller BW. The intensity dependence of auditory ERP components in unmedicated patients with major depression and healthy controls. An analysis of group differences. J Affect Disord. 2007;103(1-3):139-45. [PMID: 17316822]

22. Paige SR, Fitzpatrick DF, Kline JP, Balogh SE, Hendricks SE. Event-related potential amplitude/intensity slopes predict response to antidepressants. Neuropsychobiology. 1994; 30(4):197-201. [PMID: 7862269]

23. Lee TW, Yu YW, Chen TJ, Tsai SJ. Loudness dependence of the auditory evoked potential and response to antidepressants in Chinese patients with major depression. J Psychiatry Neurosci. 2005;30(3):202-5. [PMID: 15944745]

24. Gallinat J, Bottlender R, Juckel G, Munke-Puchner A, Stotz G, Kuss HJ, Mavrogiorgou P, Hegerl U. The loudness dependency of the auditory evoked N1/P2-component as a predictor of the acute SSRI response in depression. Psychopharmacology (Berl). 2000;148(4):404-11.

[PMID: 10928314] 
25. Kähkönen S, Jääskeläinen IP, Pennanen S, Liesivuori J, Ahveninen J. Acute trytophan depletion decreases intensity dependence of auditory evoked magnetic N1/P2 dipole source activity. Psychopharmacology (Berl). 2002;164(2): 221-27. [PMID: 12404086]

26. Debener S, Strobel A, Kürschner K, Kranczioch C, Hebenstreit J, Maercher A, Beauducel A, Brocke B. Is auditory evoked potential augmenting/reducing affected by acute tryptophan depletion? Biol Psychology. 2002;59(2):121-33. [PMID: 11911935]

27. Tuchtenhagen F, Daumann J, Norra C, Gobbelé R, Becker S, Pelz S, Sass H, Buchner H, Gouzoulis-Mayfrank E. High intensity dependence of auditory evoked dipole source activity indicates decreased serotonergic activity in abstinent ecstasy (MDMA) users. Neuropsychopharmacology. 2000;22(6):608-17. [PMID: 10788760]

28. Croft RJ, Klugman A, Baldeweg T, Gruzelier JH. Electrophysiological evidence of serotonergic impairment in longterm MDMA (“ecstasy”) users. Am J Psychiatry. 2001; 158(10):1687-92. [PMID: 11579003]

29. Daumann J, Till B, Fischermann T, Rezk M, GouzoulisMayfrank E. Intensity dependence of auditory evoked dipole source activity in polydrug ecstasy users: Evidence from an 18 months longitudinal study. J Psychopharmacol. 2006;20(2):236-44. [PMID: 16510481]

30. Hensch T, Wargelius HL, Herold U, Lesch KP, Oreland L, Brocke B. Further evidence for an association of 5-HTTLPR with intensity dependence of auditory-evoked potentials. Neuropsychopharmacology. 2006;31(9):2047-54. [PMID: 16421513]

31. Strobel A, Debener S, Schmidt D, Hünnerkopf R, Lesch $\mathrm{KP}$, Brocke B. Allelic variation in serotonin transporter function associated with the intensity dependence of the auditory evoked potential. Am J Med Genet B Neuropsychiatr Genet. 2003;118(1):41-47. [PMID: 12627465]

32. Gallinat J, Senkowski D, Wenicke C, Juckel G, Becker I, Sander T, Smolka M, Hegerl U, Rommelspacher H, Winterer G, Herrmann WM. Allelic variants of the functional promoter polymorphism of the human serotonin transporter gene is associated with auditory cortical stimulus processing. Neuropsychopharmacology. 2003;28(3):530-32. [PMID: 12629533]

33. Lesch KP, Bengel D, Heils A, Sabol SZ, Greenberg BD, Petri S, Benjamin J, Müller CR, Hamer DH, Murphy DL. Association of anxiety-related traits with a polymorphism in the serotonin transporter gene regulatory region. Science. 1996;274(5292):1527-31. [PMID: 8929413]

34. Lee HJ, Lee MS, Kang RH, Kim H, Kim SD, Kee BS, Kim YH, Kim YK, Kim JB, Yeon BK, Oh KS, Oh BH, Yoon JS, Lee C, Jung HY, Chee IS, Paik IH. Influence of the serotonin transporter promoter gene polymorphism on suscepti- bility to posttraumatic stress disorder. Depress Anxiety. 2005;21(3):135-39. [PMID: 15965993]

35. Pollock BG, Ferrell RE, Mulsant BH, Mazumdar S, Miller M, Sweet RA, Davis S, Kirshner MA, Houck PR, Stack JA, Reynolds CF, Kupfer DJ. Allelic variation in the serotonin transporter promoter affects onset of paroxetine treatment response in late-life depression. Neuropsychopharmacology. 2000;23(5):587-90. [PMID: 11027924]

36. Orr SP, Metzger LJ, Lasko NB, Macklin ML, Hu FB, Shalev AY, Pitman RK; Harvard/Veterans Affairs Post-traumatic Stress Disorder Twin Study Investigators. Physiologic responses to sudden, loud tones in monozygotic twins discordant for combat exposure: Association with posttraumatic stress disorder. Arch Gen Psychiatry. 2003:60(3): 283-88. [PMID: 12622661]

37. Blake DD, Weathers FW, Nagy LM, Kaloupek DG, Gusman FD, Charney DS, Keane TM. The development of a Clinician-Administered PTSD Scale. J Trauma Stress. 1995; 8(1):75-90. [PMID: 7712061]

38. Janes GR, Goldberg J, Eisen SA, True WR. Reliability and validity of a combat exposure index for Vietnam era veterans. J Clin Psychol. 1991;47(1):80-86. [PMID: 2026782]

39. Derogatis LR. SCL-90-R: Administration, scoring \& procedures manual-II for the revised version and other instruments of the psychopathology rating scale series. Towson (MD): Clinical Psychometric Research; 1983.

40. Jasper HH. The ten-twenty electrode system of the International Federation. J Electroencephalogr Clin Neurophysiol. 1958;10:371-75.

41. Little RC, Miliken GA, Stroup WW, Wolfinger RD. SAS system for mixed models. Cary (NC): SAS Institute; 1996.

42. Miller GA, Chapman JP. Misunderstanding analysis of covariance. J Abnorm Psychol. 2001;110(1):40-48. [PMID: 11261398]

43. Buydens-Branchey L, Noumair D, Branchey M. Duration and intensity of combat exposure and posttraumatic stress disorder in Vietnam veterans. J Nerv Ment Dis. 1990; 178(9):582-87. [PMID: 2394978]

44. Lund M, Foy D, Sipprelle C, Strachan A. The Combat Exposure Scale: A systematic assessment of trauma in the Vietnam War. J Clin Psychol. 1984;40(6):1323-38. [PMID: 6511942]

45. Koenen KC, Stellman SD, Dohrenwend BP, Sommer JF JR, Stellman JM. The consistency of combat exposure reporting and course of PTSD in Vietnam War veterans. J Trauma Stress. 2007;20(1):3-13. [PMID: 17345644]

46. Brocke B, Beauducel A, Tasche KG. Biophysiological bases and behavioral correlates of sensation seeking: Contributions to a multilevel validation. Pers Individ Dif. 1999;26(6):1103-23.

47. Graeff FG. Neurotransmitters in the dorsal periaqueductal grey and animal models of panic anxiety. In: Briley M, File 
SE, editors. New concepts in anxiety. Boca Raton (FL): CRC Press; 1991.

48. Goddard AW, Woods SW, Charney DS. A critical review of the role of norepinephrine in panic disorder: Focus on its interaction with serotonin. In: Westenberg HG, Boer JA,
Murphy DL, editors. Advances in the neurobiology of anxiety disorders. New York (NY): Wiley; 1996. p. 107-37.

Submitted for publication July 2, 2007. Accepted in revised form October 12, 2007. 